\title{
Dark-colored maple syrup treatment induces S-phase cell cycle arrest via reduced proliferating cell nuclear antigen expression in colorectal cancer cells
}

\author{
TETSUSHI YAMAMOTO, TOMOYO NISHITA and ATSUSHI TAGA \\ Pathological and Biomolecular Analyses Laboratory, School of Pharmacy, Kindai University, \\ Higashi-Osaka, Osaka 577-8502, Japan
}

Received June 28, 2018; Accepted December 17, 2018

DOI: $10.3892 / 01.2019 .9928$

\begin{abstract}
Maple syrup is a natural sweetener that is consumed worldwide. It has been previously reported that dark-colored maple syrup exerts an inhibitory effect on colorectal cancer (CRC) proliferation and invasion. In the present study, the underlying mechanism of CRC cell growth inhibition was examined with dark-colored maple syrup treatment using a shotgun liquid chromatography-tandem mass spectrometry-based global proteomic approach. Applying a semi-quantitative method based on spectral counting, 388 proteins were identified with expression changes of $>1.5$-fold following dark-colored maple syrup treatment. Gene Ontology analysis revealed that these proteins possessed cell cycle-associated functions. It was also indicated that $\mathrm{CRC}$ cells treated with dark-colored maple syrup exhibited decreased proliferating cell nuclear antigen (PCNA) expression and S-phase cell cycle arrest. Dark-colored maple syrup treatment also resulted in altered expression of cell cycle-associated genes, including cyclin-dependent kinase (CDK)4 and CDK6. In conclusion, these data suggested that dark-colored maple syrup induced S-phase cell cycle arrest in CRC cells by reducing the expression of PCNA and regulating cell cycle-associated genes. These findings suggest that dark-colored maple syrup may be a source of compounds for the development of novel drugs for colorectal cancer treatment.
\end{abstract}

Correspondence to: Dr Atsushi Taga, Pathological and Biomolecular Analyses Laboratory, School of Pharmacy, Kindai University, 3-4-1 Kowakae, Higashi-Osaka, Osaka 577-8502, Japan E-mail: punk@phar.kindai.ac.jp

Abbreviations: CRC, colorectal cancer; LC-MS/MS, liquid chromatography-tandem mass spectrometry; NSAF, normalized spectral abundance factor; PBS, phosphate-buffered saline; SEM, standard error of measurement; GO, Gene Ontology; PCNA, proliferating cell nuclear antigen; $\mathrm{CDK}$, cyclin-dependent kinase

Key words: maple syrup, colorectal cancer, proteomics, cell cycle, proliferating cell nuclear antigen

\section{Introduction}

Colorectal cancer (CRC) is one of the most commonly diagnosed types of cancer and is the second leading cause of cancer-associated mortality worldwide $(1,2)$. Etiological studies report that dietary factors serve an important role in CRC carcinogenesis (3-5). CRC risk is increased by a high intake of red and processed meats (6), as red meat is a contributing factor in the initiation of colorectal carcinogenesis (7). However, milk and other dairy products reportedly have a protective effect against $\mathrm{CRC}$, due to their high calcium content and bioactive constituents, including vitamin D (8-10). Fermented dairy products, including yogurt, also exhibit protective effects against CRC, possibly due to lactic acid bacteria and their reported ability to inactivate intestinal carcinogens and therefore reduce CRC risk (11). Although the present epidemiological evidence is insufficient (12-16), diet-associated preventative measures may be an important strategy for CRC reduction.

Maple syrup is a natural sweetener produced by boiling down sap, which is collected from the sugar maple, Acer saccharum, and is consumed worldwide by individuals of all ages $(17,18)$. The sugar maple is distributed throughout North America, and maple trees serve an important role in traditional medicine among Native Americans (19). A number of previous studies have examined the chemical composition and biological properties of maple-derived products, including maple syrup (20-26).

The climatic conditions during production season influence maple sap composition, including the color, the aroma and the taste of the maple syrup, which vary based on the season of sap collection (27-29). Maple syrup is primarily graded according to its flavor and transmittance, including visual color differences, ranging from light-colored and delicately flavored, to dark-colored and strongly flavored (18). Although the variation in composition may further lead to different grades of maple syrup, along with different biological effects, the differences in composition of ingredients among each grade of maple syrup remain unknown and require further investigation. In our previous study of the anticancer effects of different grades of maple syrup, it was reported that dark-colored maple syrup reduced AKT, also termed protein kinase $\mathrm{B}$, activation, and 
therefore significantly inhibited proliferation and invasion in CRC cells (30). In addition, another previous study showed that it significantly inhibited growth in other types of gastrointestinal cancer cell (31). This suggests that dark-colored maple syrup may be a useful dietary factor for potentially preventing cancer progression.

In the present study, a shotgun liquid chromatography-tandem mass spectrometry (LC-MS/MS)-based global proteomic analysis was performed on human CRC cells treated with different grades of maple syrup, in order to examine the underlying mechanism behind dark-colored maple syrup inhibiting CRC proliferation. Two types of maple syrup, which indicated the strongest and weakest anticancer effects in our previous study of colon cancer cells (30), were selected. A total of 388 proteins were identified that were differentially expressed in CRC cells treated with dark-grade maple syrup compared with extra-light grade maple syrup. The current study focused on the expression of proliferating cell nuclear antigen (PCNA), which is a key factor of cell cycle regulation. Therefore, further investigations were conducted on whether changes of PCNA expression following dark grade maple syrup treatment may be involved in cell cycle regulation in human CRC cells.

\section{Materials and methods}

Materials. Urea was purchased from GE Healthcare Life Sciences (Little Chalfont, UK), and thiourea and Triton X-100 were obtained from Nacalai Tesque, Inc., (Kyoto, Japan). All other chemicals and reagents were purchased from Wako Pure Chemical Industries, Ltd., (Osaka, Japan). Maple syrups were purchased at a local grocery store in Osaka, Japan, in March 2015.

Based on Canadian standards, maple syrup is classified into the following five grades: AA, extra light; grade A, light; grade $\mathrm{B}$, medium; grade $\mathrm{C}$, amber, and grade D dark. Since the present study was performed the maple syrup classification has changed according to the following: Golden, delicate Taste; amber, rich Taste; dark, robust taste; and very dark, strong taste (32). In Japan, these new grading maple syrup grades have been used since April 2017. Since the differences in ingredient composition among each grade of maple syrup are not yet fully understood, in the present study, two grades of maple syrup were selected: The extra light grade maple syrup, which has a slightly golden tint and a delicate flavor with $>75 \%$ light transmission, and the dark grade maple syrup, which has a much darker brown color and a strong flavor with $<25 \%$ light transmission.

The colorectal cancer DLD-1 cell line was purchased from the American Type Culture Collection (Manassas, VA, USA). All cells were cultured in RPMI-1640 medium supplemented with $10 \%$ fetal bovine serum (FBS; Gibco; Thermo Fisher Scientific, Inc., Waltham, MA, USA) at $37^{\circ} \mathrm{C}$ in an atmosphere containing $5 \% \mathrm{CO}_{2}$.

Protein preparation. The DLD-1 cells were plated at a density of $2 \times 10^{5}$ cells/60-mm dish with RPMI-1640 medium. The next day, the culture medium was replaced with culture medium with $1 \%$ (v/v) extra light grade maple syrup (extra), dark grade maple syrup (dark) or without syrup (control). This concentration was selected due to results from our previous study indicating a lack of cytotoxic effects against DLD-1 cells due to the high concentration of sucrose (30). After $72 \mathrm{~h}$, the cells were solubilized in urea lysis buffer ( $7 \mathrm{M}$ urea, $2 \mathrm{M}$ thiourea, 5\% 3-[(3-Cholamidopropyl) dimethylammonio] propanesulfonate and $1 \%$ Triton X-100), and the protein concentration was measured with the Bio-Rad Protein assay (cat. no. 5000006JA; Bio-Rad Laboratories Inc., Hercules, CA, USA), according to the manufacturer's protocols.

Gel-free digestion was subsequently performed, as described previously (33). Briefly, $10 \mu \mathrm{g}$ protein extract from each sample was reduced by adding $45 \mathrm{mM}$ dithiothreitol and $20 \mathrm{mM}$ tris (2-carboxyethyl) phosphine. The proteins were subsequently alkylated with $100 \mathrm{mM}$ iodoacetic acid. Following alkylation, the samples were digested at $37^{\circ} \mathrm{C}$ for $24 \mathrm{~h}$ using MS-grade trypsin gold (Promega Corporation, Madison, WI, USA). Finally, the digests were purified using PepClean C-18 Spin Columns (Thermo Fisher Scientific, Inc.), according to the manufacturer's protocol.

Liquid chromatography tandem-mass spectrometry (LC-MS/MS) analysis for protein identification. Peptide samples $(\sim 2 \mu \mathrm{g})$ were injected into a peptide L-trap column (Chemicals Evaluation and Research Institute, Tokyo, Japan) with an HTC PAL autosampler (CTC Analytics AG, Zwingen, Switzerland). The samples were subsequently further separated through a Paradigm MS4 (AMR Inc., Tokyo, Japan) with a reverse-phase C18-column (L-column, 3- $\mu$ m-diameter gel particles, $120 \AA$ A pore size, $0.2 \times 150 \mathrm{~mm}$; Chemicals Evaluation and Research Institute, Tokyo, Japan). The column flow rate was $1 \mu \mathrm{l} / \mathrm{min}$, and the mobile phase consisted of $0.1 \%$ formic acid in water (solution A) and acetonitrile (solution B), with a concentration gradient of $5 \%$ solution B to $40 \%$ solution B over $120 \mathrm{~min}$. Gradient-eluted peptides were introduced into the mass spectrometer through the nanoelectrospray ionization (NSI) interface that had a separation column outlet directly connected with an NSI needle. The peptides were analyzed with an LTQ ion-trap mass spectrometer (Thermo Fisher Scientific, Inc.). No sheath or auxiliary gas was used. The MS scan sequence used was full-scan MS in the normal/centroid mode and sequential MS/MS in the normal/centroid mode. The positive ion mass spectra were acquired in a data-dependent manner, with MS/MS fragmentation performed on the two most intense peaks of every full MS scan with an isolation width of $1.0 \mathrm{~m} / \mathrm{z}$ and a collisional activation amplitude of $35 \%$ in the $\mathrm{m} / \mathrm{z}$ range of $300-2,000$.

All MS/MS spectral data were searched against the SwissProt Homo Sapiens database (https://www.uniprot.org/) using Mascot version 2.4.01 (Matrix Science, Ltd., London, UK). The search criteria were 'enzyme' and 'trypsin', with the following allowances: $\leq 2$ missed cleavage peptides; mass tolerance, $\pm 2.0 \mathrm{Da}$; MS/MS tolerance, $\pm 0.8 \mathrm{Da}$; cysteine carbamidomethylation; and methionine oxidation modifications.

Semi-quantitative analysis of identified proteins. The fold-change in expression was calculated as the $\log 2$ ratio of protein abundance (Rsc), evaluated by spectral counting (34). For comparisons, the relative amounts of identified proteins were calculated using the normalized spectral abundance factor (NSAF) (35). Differentially expressed proteins were 
considered significant when the Rsc was $>0.585$ or $<-0.585$, corresponding to fold-changes of $>1.5$ or $<0.66$, respectively.

Gene ontology $(G O)$ analysis. The functions of proteins that indicated altered expression with maple syrup treatment were additionally investigated. Their sequences were assigned to Kyoto Encyclopedia of Genes and Genomes (https://www. genome.jp/kegg/kegg_ja.html) signaling pathway terms to examine their functional annotations using the Database for Annotation, Visualization, and Integrated Discovery (DAVID) version 6.8 (http://david.abcc.ncifcrf.gov/home.jsp) (36-38). $\mathrm{P}<0.05$ was considered to indicate a significant category.

Western blot analysis. Total protein $(5 \mu \mathrm{g})$ that had been prepared as aforementioned was mixed with loading buffer and boiled at $95^{\circ} \mathrm{C}$ for $10 \mathrm{~min}$. The proteins were then separated on a $12 \%$ SDS-PAGE gel. The separated proteins were transferred to polyvinylidene fluoride membranes (Merck KGaA, Darmstadt, Germany) for 30 min at $15 \mathrm{~V}$. Following blocking in TBS-Tween-20 (0.1\%) buffer (Cell Signaling Technology, Inc., Danvers, MA, USA) with 5\% skimmed milk for $2 \mathrm{~h}$ at room temperature, the membranes were incubated with an anti- PCNA antibody (1:20,000; cat. no. 13110; Cell Signaling Technology, Inc.) at $4^{\circ} \mathrm{C}$ overnight. The membranes were subsequently washed and incubated with horseradish peroxidase-conjugated anti-rabbit immunoglobulin(Ig)G antibody (1:4,000; cat . no. A106PU; American Qualex, San Clemente, CA, USA) at room temperature for $1 \mathrm{~h}$. The blots were washed and visualized with SuperSignal West Dura Extended Duration substrate (Thermo Fisher Scientific, Inc.). The bands were analyzed with the myECL Imager system 2.0 software (Thermo Fisher Scientific, Inc.). The membranes were subsequently stripped by Restore Western Blot Stripping buffer (Thermo Fisher Scientific, Inc.), and the same membranes were re-probed with an anti- $\beta$-actin antibody (1:5,000 dilution; cat. no. sc-47778; Santa Cruz Biotechnology, Inc., Dallas, TX, USA) at $4^{\circ} \mathrm{C}$ overnight, which served as the protein loading control. The relative quantities of PCNA over $\beta$-actin were used to evaluate PCNA expression under different conditions. All western blot analyses were performed as three independent experiments.

Cell cycle analysis by flow cytometry. To analyze cell cycle distribution, DNA was stained with propidium iodide (PI; Nacalai Tesque, Inc., Kyoto, Japan). Briefly, DLD-1 cells were plated at a density of $2 \times 10^{5}$ cells/100-mm dish in culture medium. The next day, the culture medium was replaced with $1 \%$ (v/v) extra light grade maple syrup (Extra), dark grade maple syrup (Dark) or without syrup (control). Following $72 \mathrm{~h}$ of incubation at $37^{\circ} \mathrm{C}$, the cells were washed with PBS and fixed in ice-cold $70 \%$ ethanol at $4^{\circ} \mathrm{C}$ for $2 \mathrm{~h}$. The cells were subsequently treated with $0.25 \mathrm{mg} / \mathrm{ml}$ RNase in PBS for $60 \mathrm{~min}$ at $37^{\circ} \mathrm{C}$, followed by staining with $50 \mu \mathrm{g} / \mathrm{ml}$ PI in PBS for $30 \mathrm{~min}$ at $4^{\circ} \mathrm{C}$ in the dark. Cell proportion in different phases of the cell cycle was determined using a BD LSRFortessa flow cytometer (BD Biosciences, San Jose, CA, USA) and analyzed using FACS DIVA software v8.0.1 (BD Biosciences).

Reverse transcription-quantitative polymerase chain reaction $(R T-q P C R)$ using TaqMan array analysis. Total RNA was extracted from treated DLD-1 cells using the GenElute
Mammalian Total RNA Miniprep kit (cat. no. RTN70-1KT; Sigma-Aldrich; Merck KGaA), according to the manufacturer's protocols. From the extracted RNA, cDNA was synthesized using the High Capacity cDNA Reverse Transcription kit (cat. no. 4368814; Thermo Fisher Scientific, Inc.), according to the manufacturer's protocols. Analysis was performed using TaqMan Array Human Cyclins \& Cell Cycle Regulation 96-Well Plates (cat. no. 4414123; Thermo Fisher Scientific, Inc.) in the 7500 system (Applied Biosystems; Thermo Fisher Scientific, Inc.), according to the manufacturer's protocols. The thermocycling conditions were as follows: Denaturation at $95^{\circ} \mathrm{C}$ for $20 \mathrm{sec}$, followed by 40 cycles of amplification at $95^{\circ} \mathrm{C}$ for $3 \mathrm{sec}$ and $60^{\circ} \mathrm{C}$ for $30 \mathrm{sec}$. The relative gene expression was calculated using the $2^{-\Delta \Delta \mathrm{Cq}}$ method (39-43). The $\Delta \Delta \mathrm{Cq}$ method uses the normalized $\Delta \mathrm{Cq}$ value of each sample, which was calculated with $18 \mathrm{~S}$ rRNA as the endogenous control gene. The $\Delta \Delta \mathrm{Cq}$ value is the difference between treated and control samples. Finally, the fold-change was determined as $2^{-\Delta \Delta C q}$.

Statistical analysis. All experiments were repeated at a minimum of three times. All data are presented as the mean \pm standard error of the mean (SEM). The data were analyzed by one-way analysis of variance followed by Tukey's post hoc test. $\mathrm{P}<0.05$ was considered to indicate a statistically significant difference. Computations were performed using GraphPad Prism version 5 (GraphPad Software Inc., La Jolla, CA, USA).

\section{Results}

Identification and semi-quantitative comparisons of differentially expressed proteins in maple syrup-treated DLD-1 cells. To investigate the inhibitory effects of maple syrup on CRC proliferation, shotgun proteomics was used to examine the molecular profile of proteins that were regulated by maple syrup treatment. Applying the aforementioned search parameters, a total of 575 proteins were identified in DLD-1 cells treated with extra light grade maple syrup, and 549 proteins in DLD-1 cells treated with dark-colored maple syrup. Proteins were categorized into the 'Extra' and 'Dark' groups accordingly.

The proteins expressed in maple syrup-treated DLD-1 cells were further evaluated using a label-free semi-quantitative method based on spectral counting. The Rsc values were calculated for the proteins identified in the Extra and Dark groups. A positive Rsc value indicated increased expression with dark-colored maple syrup treatment, and a negative value indicated reduced expression with dark-colored maple syrup treatment (Fig. 1; light grey area). The NSAF value was also calculated for each protein identified in the Extra and Dark groups. Proteins with a $>0.585$ and $<-0.585$ Rsc value were considered candidate dark-colored maple syrup-regulated proteins.

This semi-quantitative procedure resulted in the identification of 388 proteins that were differentially expressed with dark-colored maple syrup treatment (data not shown). Maple syrup treatment did not alter the expression of housekeeping proteins, including glyceraldehyde-3-phosphate dehydrogenase and histone H4 (Fig. 1).

Functional annotation of proteins regulated by maple syrup. GO analysis of the candidate dark-colored maple 


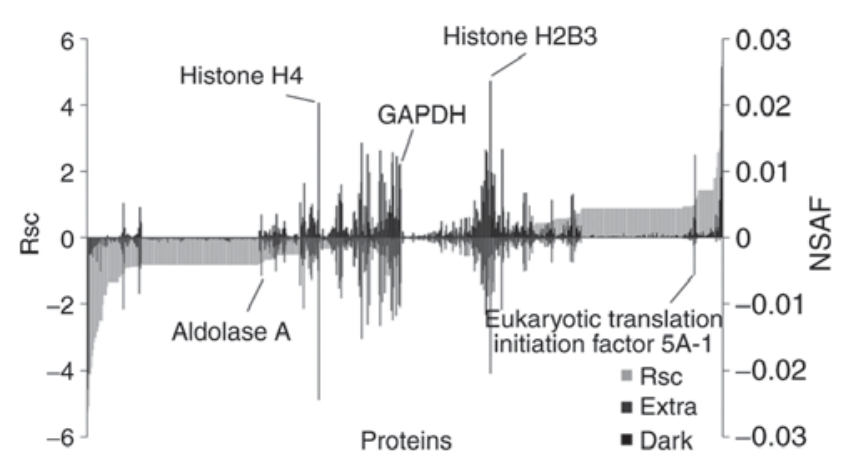

Figure 1. Semi-quantitative comparison of proteins differentially expressed in maple syrup-treated DLD-1 cells. For the identified proteins, Rsc and NSAF values were calculated to compare protein expression levels between DLD-1 cells treated with extra light maple syrup vs. dark-colored maple syrup. Proteins are positioned along the x-axis, according to Rsc value, increasing from left to right (light grey area). NSAF values are indicated for the Extra group (below the axis; grey bar) and for the Dark group (above the axis; black bar). Proteins highly expressed in the Extra and Dark groups, respectively, are near the left and right sides of the x-axis. Housekeeping proteins are located near the center of the $\mathrm{x}$-axis. Rsc, $\log 2$ ratio of protein abundance; NSAF, normalized spectral abundance factor; Extra, extra light maple syrup; Dark, dark-colored maple syrup.

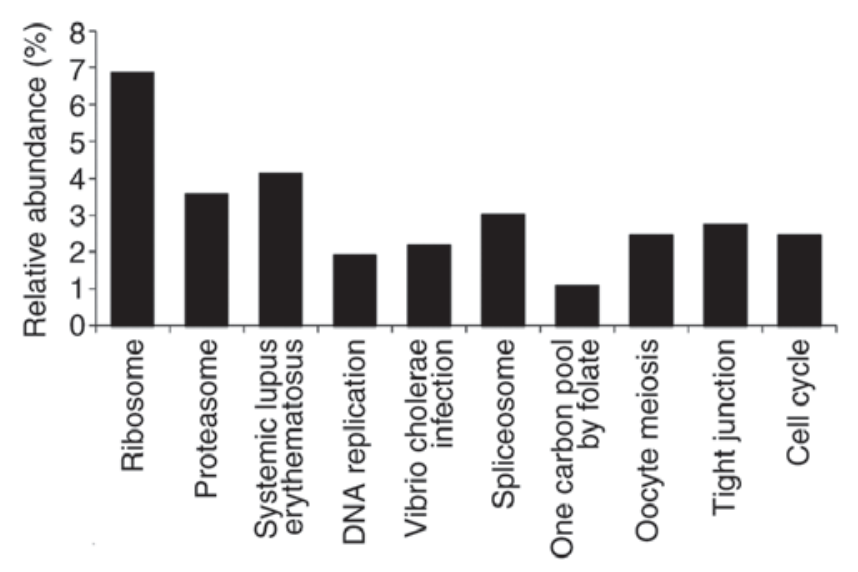

Figure 2. Gene Ontology analysis of identified proteins. Differentiallyexpressed proteins were assigned to Kyoto Encyclopedia of Genes and Genomes signaling pathway terms. Only significant categories are presented $(\mathrm{P}<0.05)$.

syrup-regulated proteins was performed. GO terms associated with 'pathway' were searched for in DAVID (Fig. 2), and the focus was on proteins classified as associated with the 'cell cycle' (Table I).

Effects of maple syrup on PCNA expression in DLD-1 cells. The expression of PCNA protein in maple syrup-treated DLD-1 cells was examined. The results of the present study indicated a significant decrease in PCNA expression with dark-colored maple syrup treatment (Dark) compared with that in the cells treated with extra light grade maple syrup treatment (Extra) and the untreated (control) cells (Fig. 3).

Effects of maple syrup on cell cycle progression of CRC cells. The present study also investigated whether the dark-colored maple syrup-induced decrease in PCNA expression affected cell cycle progression in DLD-1 cells. Flow cytometry analysis
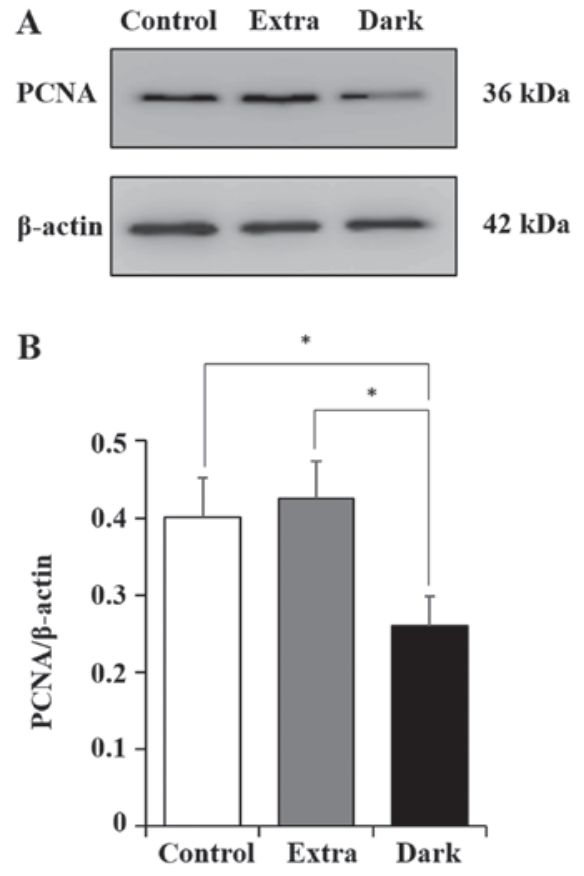

Figure 3. PCNA expression in maple syrup-treated DLD-1 cells. (A) Western blot analysis indicated the expression levels of PCNA in DLD-1 cells treated in the control group (without maple syrup) and in the two maple syrup groups, the Extra and Dark groups. (B) Quantification of western blot analysis results. Data is presented as the mean \pm standard error of the mean of three independent experiments in maple syrup-treated DLD-1 cells. ${ }^{*} \mathrm{P}<0.05$. PCNA, proliferating cell nuclear antigen; Extra, extra light maple syrup; Dark, dark-colored maple syrup.

revealed a significantly increased cell population in the $S$ phase $(P<0.01)$, and a decreased population in the $G_{2} / M$ phase $(\mathrm{P}<0.05)$ in the Dark group compared with that in the Extra group and the control group (Fig. 4A and B).

Effects of maple syrup on the expression of cell cycle-associated factors in CRC cells. Using the TaqMan Array Human Cyclins \& Cell Cycle Regulation 96-Well Plate, qPCR was conducted to examine the molecular profile of cell cycle-associated mRNAs that were regulated by maple syrup treatment. RT-qPCR analysis was performed with DLD-1 cells treated with extra light or dark-colored maple syrup. In the Dark group, fold-changes were induced in the relative expression of cell cycle-associated factors. Expression levels in the Extra group were set as 1, and the fold-changes following dark-colored maple syrup treatment were evaluated using the DDCq method. Among the 44 tested cell cycle-associated genes, 12 genes indicated changes in expression of $>2$-fold in DLD-1 cells treated with dark-colored maple syrup treatment compared with extra light grade maple syrup (Fig. 5). It was indicated that dark-colored maple syrup treatment reduced cyclin-dependent kinase 4 (CDK4), CDK6 and transforming growth factor $\beta 1$ (TGFB1) expression, and induced cyclin-dependent kinase inhibitor $2 \mathrm{~B}$ (CDKN2B) expression (Fig. 5).

\section{Discussion}

In the present study, a gel-free LC-MS/MS-based proteomics approach was applied to examine the underlying mechanism of CRC cell growth inhibition by dark-colored maple syrup. 
Table I. Proteins categorized as associated with the 'cell cycle' in Gene Ontology analysis.

Accession number

P33992

P49736

P33991

P12004

P62258

Q14566

Q13547N

P61981

P27348
Description

Fold-change (Rsc)

DNA replication licensing factor MCM5

$-0.812$

DNA replication licensing factor MCM2

$-0.812$

DNA replication licensing factor MCM4

$-0.812$

Proliferating cell nuclear antigen

$-0.781$

14-3-3 protein $\varepsilon$

$-0.648$

DNA replication licensing factor MCM6

0.884

Histone deacetylase 1

0.884

14-3-3 protein $\gamma$

2.107

2.573

Rsc, $\log 2$ ratio of protein abundance.
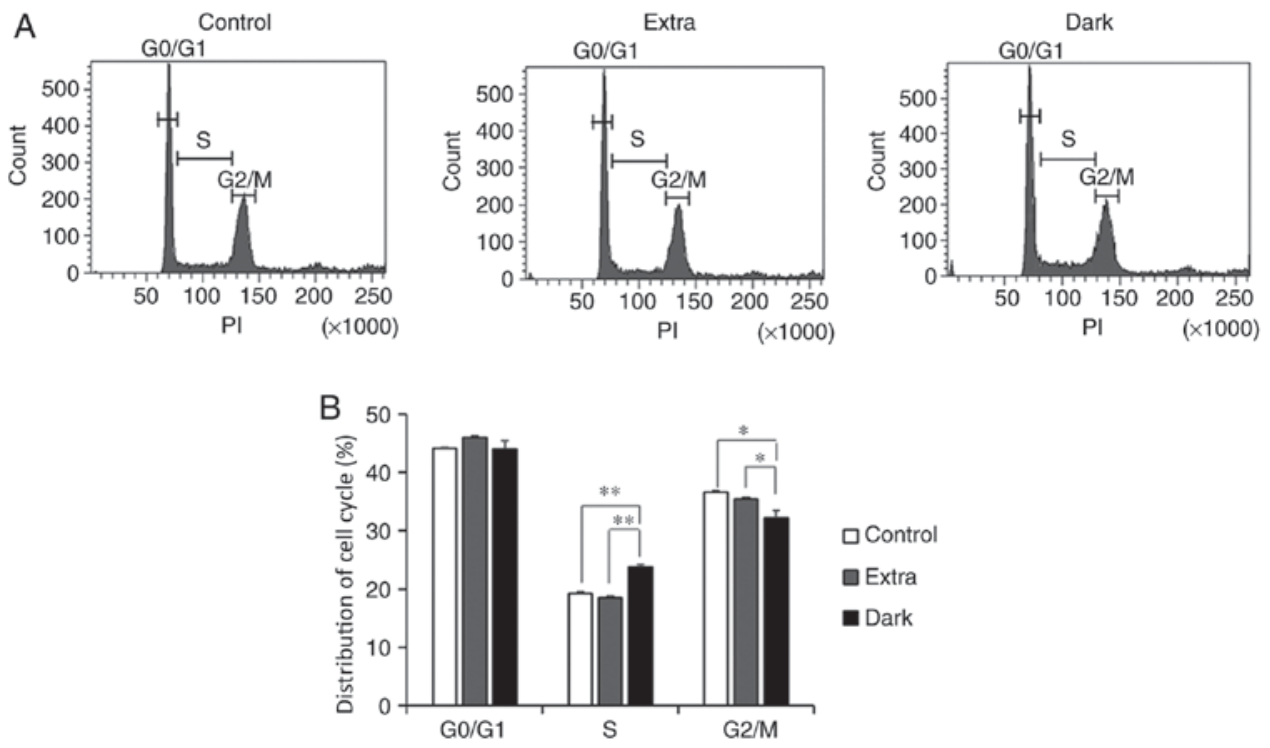

Figure 4. Flow cytometry analysis of cell cycle progression in maple syrup-treated DLD-1 cells. (A) Representative histograms of cell cycle distribution in maple syrup-treated DLD-1 cells. (B) Data is presented as the mean \pm standard error of the mean of three independent experiments in maple syrup-treated DLD-1 cells. " $\mathrm{P}<0.05$ and ${ }^{* *} \mathrm{P}<0.01$. PI, propidium iodide; Extra, extra light maple syrup; Dark, dark-colored maple syrup.

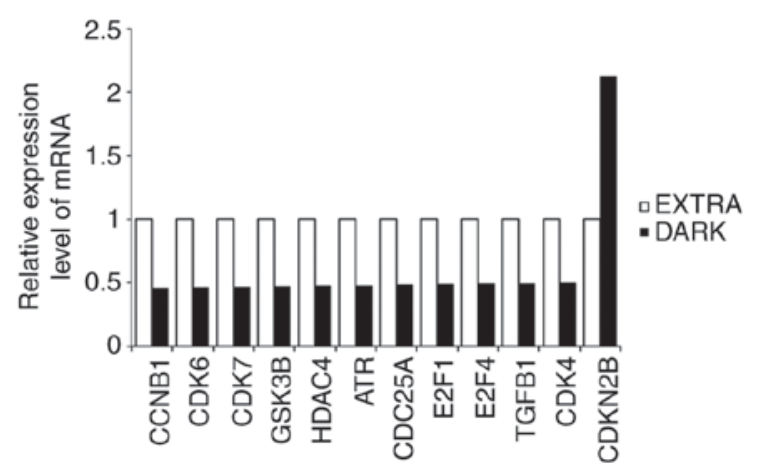

Figure 5. Expression profile of cell cycle-associated genes in maple syrup-treated DLD-1 cells, based on polymerase chain reaction array analysis. Extra, extra light maple syrup; Dark, dark-colored maple syrup; CCNB1, cyclin B1; CDK6, cyclin-dependent kinase 6; CDK7, cyclin-dependent kinase 7; GSK3B, glycogen synthase kinase 3 beta; HDAC4, histone deacetylase 4; ATR, ATR serine/threonine kinase; CDC25A, cell division cycle 25A; E2F1, E2F transcription factor 1; E2F4, E2F transcription factor 4; TGFB1, transforming growth factor, beta 1 ; CDK4, cyclin-dependent kinase 4; CDKN2B, cyclin-dependent kinase inhibitor $2 \mathrm{~B}$.
Using a semi-quantitative method of spectral counting, a total of 388 proteins were identified that indicated $>1.5$-fold changes in expression following maple syrup treatment. The roles of these identified proteins were examined with GO analysis, focusing on the functions of proteins classified as associated with the 'cell cycle', since these proteins serve important roles in the proliferation system. The study also focused on PCNA, which is a member of this pathway. A western blot analysis was subsequently performed to validate the spectral counting results, and to determine whether dark-colored maple syrup treatment led to decreased PCNA expression in DLD-1 cells.

PCNA has been reported to exhibit different behaviors depending on the cell cycle phase, and serves important roles in DNA replication and DNA repair (44-47). PCNA also recruits chromatin remodeling and epigenetic modification factors (48). During the S phase of the cell cycle, PCNA is reportedly localized in the active replication site, and has the ability to differentiate between early, mid and late 
$\mathrm{S}$ phase $(49,50)$. Therefore, PCNA expression is considered to be associated with $\mathrm{S}$-phase cell cycle progression.

The present study observed that dark-colored maple syrup treatment decreased PCNA expression, which induced the S-phase cell cycle arrest of DLD-1 cells. Previous reports also indicate that induction of S-phase cell cycle arrest is accompanied by decreased PCNA expression in a number of tumor cells, including in CRC cells treated with functional compounds, such as resveratrol and oxoaporphine metal complexes $(51,52)$. Previous data also indicate that the induction of S-phase cell cycle arrest is associated with changes in the expression of cyclins and CDKs in these cells. Therefore, maple syrup treatment may influence the cell cycle-associated gene expression in CRC cells. Accordingly, we hypothesized that dark-colored maple syrup induced S-phase cell cycle arrest in DLD-1 cells, which may affect the expression of cell cycle-associated genes. The study findings supported this hypothesis.

CDK4/6 is a key kinase in cell cycle promotion, and is currently considered a molecular target for anticancer drug development $(53,54)$. The CDK4/6 inhibitor palbociclib is clinically used for the treatment of advanced breast cancer $(55,56)$. The results of the present study support the possibility that the bioactive compounds in dark-colored maple syrup may be useful in the development of novel anticancer drugs for treatment of $\mathrm{CRC}$ and other types of advanced cancer. In addition, CDKN2B is also known as a cell-cycle regulator via its interaction with CDK4 and CDK6, and tumor suppressor genes, including p53 and p18 (57). Therefore, it can by hypothesized that the bioactive compounds, which have been indicated to upregulate CDKN2B expression may be present in dark grade maple syrup and may be a useful resource in developing novel anticancer drugs. In addition, these bioactive compounds may have an inhibitory effect on the TGF signaling pathway by suppressing TGF- $\beta 1$ expression by upregulating CDNK2B expression, since previous reports demonstrated that downregulation of CDKN2B expression induced an increase of TGF $\beta 1$ expression in human smooth muscle cells and umbilical vein endothelial cells (58). A previous study reported that the ginnalins-polyphenols that are present in maple syrup inhibit proliferation through S-phase cell cycle arrest (59). However, the effects of ginnalins on PCNA, CDK4/6 and CDKN2B expression in CRC cells are not well understood. Further studies are required to identify the bioactive compounds in dark-colored maple syrup that are responsible for inhibiting the expression of PCNA, CDK4/6 and/or CDKN2B, and therefore, inducing cell cycle arrest. Further clarification is required in order to examine whether dark-colored maple syrup inhibits proliferation through S-phase cell cycle arrest by regulating cell cycle-associated gene expression in other types of cancer cells.

In conclusion, the present study indicated that dark-colored maple syrup induced S-phase cell cycle arrest in CRC cells by reducing PCNA expression and regulating cell cycle-associated genes. These findings suggest that dark-colored maple syrup may be a useful dietary factor, with a potential preventative effect against CRC. Compounds in dark-colored maple syrup may also be useful for the development of novel anticancer drugs for colorectal cancer treatment.

\section{Acknowledgements}

Not applicable.

\section{Funding}

The present study was supported in part by the MEXT-Supported Program of the Strategic Research Foundation at Private Universities (grant no. S1411037).

\section{Availability of data and materials}

All data generated or analyzed during this study are included in this published article.

\section{Authors' contributions}

TY and AT designed the study and analyzed the data. TY and TN performed the experiments. TY drafted the manuscript. AT critically evaluated the study and the final version of the manuscript. All authors participated in discussion of the work and approved the final manuscript.

\section{Ethics approval and consent to participate}

Not applicable.

\section{Patient consent for publication}

Not applicable.

\section{Competing interests}

The authors declare that they have no competing interests.

\section{References}

1. Tariq K and Ghias K: Colorectal cancer carcinogenesis: A review of mechanisms. Cancer Biol Med 13: 120-135, 2016.

2. Mármol I, Sánchez-de-Diego C, Pradilla Dieste A, Cerrada E and Rodriguez Yoldi MJ: Colorectal carcinoma: A general overview and future perspectives in colorectal cancer. Int J Mol Sci 18: pii: E197, 2017.

3. Armstrong B and Doll R: Environmental factors and cancer incidence and mortality in different countries, with special reference to dietary practices. Int J Cancer 15: 617-631, 1975.

4. Doll R and Peto R: The causes of cancer: Quantitative estimates of avoidable risks of cancer in the United States today. J Natl Cancer Inst 66: 1191-1308, 1981.

5. Song M, Garrett WS and Chan AT: Nutrients, foods, and colorectal cancer prevention. Gastroenterology 148: 1244-1260. e16, 2015

6. Chan DS, Lau R, Aune D, Vieira R, Greenwood DC, Kampman E and Norat T: Red and processed meat and colorectal cancer incidence: Meta-analysis of prospective studies. PLoS One 6: e20456, 2011.

7. Chao A, Thun MJ, Connell CJ, McCullough ML, Jacobs EJ, Flanders WD, Rodriguez C, Sinha R and Calle EE: Meat consumption and risk of colorectal cancer. JAMA 293: 172-182, 2005.

8. Holt PR, Atillasoy EO, Gilman J, Guss J, Moss SF, Newmark H, Fan K, Yang K and Lipkin M: Modulation of abnormal colonic epithelial cell proliferation and differentiation by low-fat dairy foods: A randomized controlled trial. JAMA 280: 1074-1079, 1998.

9. Glinghammar B, Venturi M, Rowland IR and Rafter JJ: Shift from a dairy product-rich to a dairy product-free diet: Influence on cytotoxicity and genotoxicity of fecal water-potential risk factors for colon cancer. Am J Clin Nutr 66: 1277-1282, 1997.

10. Norat T and Riboli E: Dairy products and colorectal cancer. A review of possible mechanisms and epidemiological evidence. Eur J Clin Nutr 57: 1-17, 2003. 
11. Wollowski I, Ji ST, Bakalinsky AT, Neudecker C and Pool-Zobel BL: Bacteria used for the production of yogurt inactivate carcinogens and prevent DNA damage in the colon of rats. J Nutr 129: 77-82, 1999.

12. Kesse E, Boutron-Ruault MC, Norat T, Riboli E and Clavel-Chapelon F; E3N Group: Dietary calcium, phosphorus, vitamin $\mathrm{D}$, dairy products and the risk of colorectal adenoma and cancer among French women of the E3N-EPIC prospective study. Int J Cancer 117: 137-144, 2005.

13. Cho E, Smith-Warner SA, Spiegelman D, Beeson WL, van den Brandt PA, Colditz GA, Folsom AR, Fraser GE, Freudenheim JL, Giovannucci E, et al: Dairy foods, calcium, and colorectal cancer: A pooled analysis of 10 cohort studies. J Nat Cancer Inst 96: 1015-1022, 2004.

14. Giovannucci E, Rimm EB, Stampfer MJ, Colditz GA, Ascherio A and Willett WC: Intake of fat, meat, and fiber in relation to risk of colon cancer in men. Cancer Res 54: 2390-2397, 1994.

15. Park Y, Leitzmann MF, Subar AF, Hollenbeck A and Schatzkin A: Dairy food, calcium, and risk of cancer in the NIH-AARP diet and health study. Arch Intern Med 169: 391-401, 2009.

16. Lee SA, Shu XO, Yang G, Li H, Gao YT and Zheng W: Animal origin foods and colorectal cancer risk: A report from the Shanghai Women's health study. Nutr Cancer 61: 194-205, 2009.

17. Ball DW: The chemical composition of maple syrup. J Chem Educ 84: 1647, 2007.

18. Perkins TD and van den Berg AK: Maple syrup-production, composition, chemistry, and sensory characteristics. Adv Food Nutr Res 56: 101-143, 2009.

19. Arnason T, Hebda RJ and Johns T: Use of plants for food and medicine by Native Peoples of eastern Canada. Can J Bot 59 2189-2325, 1981

20. Apostolidis E, Li L, Lee C and Seeram NP: In vitro evaluation of phenolic-enriched maple syrup extracts for inhibition of carbohydrate hydrolyzing enzymes relevant to type 2 diabetes management. J Funct Foods 3: 100-106, 2011.

21. Legault J, Girard-Lalancette K, Grenon C, Dussault C and Pichette A: Antioxidant activity, inhibition of nitric oxide overproduction, and in vitro antiproliferative effect of maple sap and syrup from Acer saccharum. J Med Food 13: 460-468, 2010.

22. González-Sarrías A, Li L and Seeram NP: Effects of maple (Acer) plant part extracts on proliferation, apoptosis and cell cycle arrest of human tumorigenic and non-tumorigenic colon cells. Phytother Res 26: 995-1002, 2012.

23. Theriault M, Caillet S, Kermasha S and Lacroix M: Antioxidant antiradical and antimutagenic activities of phenolic compounds present in maple products. Food Chem 98: 490-501, 2006.

24. Hawco CL, Wang Y, Taylor M and Weaver DF: A maple syrup extract prevents $\beta$-amyloid aggregation. Can J Neurol Sci 43: 198-201, 2016.

25. Nagai $\mathrm{N}$, Ito $\mathrm{Y}$ and Taga A: Comparison of the enhancement of plasma glucose levels in type 2 diabetes otsuka long-evans tokushima fatty rats by oral administration of sucrose or maple syrup. J Oleo Sci 62: 737-743, 2013.

26. Nagai N, Yamamoto T, Tanabe W, Ito Y, Kurabuchi S, Mitamura K and Taga A: Changes in plasma glucose in otsuka long-evans tokushima fatty rats after oral administration of maple syrup. J Oleo Sci 64: 331-335, 2015

27. Kim YT and Leech RH: Effects of climatic conditions on sap flow in sugar maple. Forest Chron 61: 303-307, 1985.

28. Marvin JW and Erickson RO: A statistical evaluation of some of the factors responsible for the flow of sap from the sugar maple. Plant Physiol 31: 57-61, 1956.

29. Houle D, Paquette A, Côté B, Logan T, Power H, Charron I and Duchesne L: Impacts of climate change on the timing of the production season of maple syrup in Eastern Canada. PLoS One 10: e0144844, 2015.

30. Yamamoto T, Uemura K, Moriyama K, Mitamura K and Taga A Inhibitory effect of maple syrup on the cell growth and invasion of human colorectal cancer cells. Oncol Rep 33: 1579-1584, 2015.

31. Yamamoto T, Sato K, Kubota Y, Mitamura K and Taga A: Effect of dark-colored maple syrup on cell proliferation of human gastrointestinal cancer cell. Biomed Rep 7: 6-10, 2017.

32. Maple products regulation: https://laws-lois.justice gc.ca/eng/regulations/C.R.C., c. 289/page-8.html\#h-24

33. Bluemlein $\mathrm{K}$ and Ralser M: Monitoring protein expression in whole-cell extracts by targeted label- and standard-free LC-MS/MS. Nat Protoc 6: 859-869, 2011.

34. Old WM, Meyer-Arendt K, Aveline-Wolf L, Pierce KG, Mendoza A, Sevinsky JR, Resing KA and Ahn NG: Comparison of label-free methods for quantifying human proteins by shotgun proteomics. Mol Cell Proteomics 4: 1487-1502, 2005.
35. Zybailov B, Coleman MK, Florens L and Washburn MP: Correlation of relative abundance ratios derived from peptide ion chromatograms and spectrum counting for quantitative proteomic analysis using stable isotope labeling. Anal Chem 77: 6218-6224, 2005.

36. Dennis G Jr, Sherman BT, Hosack DA, Yang J, Gao W, Lane HC and Lempicki RA: DAVID: Database for annotation, visualization, and integrated discovery. Genome Biol 4: P3, 2003.

37. Huang da W, Sherman BT and Lempicki RA: Systematic and integrative analysis of large gene lists using DAVID bioinformatics resources. Nat Protoc 4: 44-57, 2009.

38. Huang da W, Sherman BT and Lempicki RA: Bioinformatics enrichment tools: Paths toward the comprehensive functional analysis of large gene lists. Nucleic Acids Res 37: 1-13, 2009.

39. Parikh P, Bai H, Swartz MF, Alfieris GM and Dean DA: Identification of differentially regulated genes in human patent ductus arteriosus. Exp Biol Med (Maywood) 241: 2112-2118, 2016.

40. Livak KJ and Schmittgen TD: Analysis of relative gene expression data using real-time quantitative PCR and the 2(-Delta Delta C(T)) method. Methods 25: 402-408, 2001.

41. Carbotti G, Nikpoor AR, Vacca P, Gangemi R, Giordano C, Campelli F, Ferrini S and Fabbi M: IL-27 mediates HLA class I up-regulation, which can be inhibited by the IL- 6 pathway, in HLA-deficient small cell lung cancer cells. J Exp Clin Cancer Res 36: 140, 2017.

42. Adnan M, Morton G and Hadi S: Analysis of rpoS and bolA gene expression under various stress-induced environments in planktonic and biofilm phase using $2(-\Delta \Delta \mathrm{CT})$ method. Mol Cell Biochem 357: 275-282, 2011.

43. Soejima M and Koda Y: TaqMan-based real-time polymerase chain reaction for detection of FUT2 copy number variations: Identification of novel Alu-mediated deletion. Transfusion 51: 762-769, 2011.

44. Kelman Z: PCNA: Structure, functions and interactions. Oncogene 14: 629-640, 1997.

45. Majka J and Burgers PM: The PCNA-RFC families of DNA clamps and clamp loaders. Prog Nucleic Acid Res Mol Biol 78: 227-260, 2004.

46. Moldovan GL, Pfander B and Jentsch S: PCNA, the maestro of the replication fork. Cell 129: 665-679, 2007.

47. Bártová E, Suchánková J, Legartová S, Malyšková B, Hornáček M, Skalníková M, Mašata M, Raška I and Kozubek S: PCNA is recruited to irradiated chromatin in late $\mathrm{S}$-phase and is most pronounced in G2 phase of the cell cycle. Protoplasma 254: 2035-2043, 2017.

48. Budhavarapu VN, Chavez M and Tyler JK: How is epigenetic information maintained through DNA replication? Epigenetics Chromatin 6: 32, 2013.

49. Celis JE and Celis A: Cell cycle-dependent variations in the distribution of the nuclear protein cyclin proliferating cell nuclear antigen in cultured cells: Subdivision of S phase. Proc Natl Acad Sci USA 82: 3262-3266, 1985.

50. Schönenberger F, Deutzmann A, Ferrando-May E and Merhof D: Discrimination of cell cycle phases in PCNA-immunolabeled cells. BMC Bioinformatics 16: 180, 2015.

51. Liu B, Zhou Z, Zhou W, Liu J, Zhang Q, Xia J, Liu J, Chen N, Li M and Zhu R: Resveratrol inhibits proliferation in human colorectal carcinoma cells by inducing G1/S-phase cell cycle arrest and apoptosis through caspase/cyclin-CDK pathways. Mol Med Rep 10: 1697-1702, 2014.

52. Qin JL, Shen WY, Chen ZF, Zhao LF, Qin QP, Yu YC and Liang H: Oxoaporphine metal complexes $\left(\mathrm{Co}^{\mathrm{II}}, \mathrm{Ni}^{\mathrm{II}}, \mathrm{Zn}^{\mathrm{II}}\right)$ with high antitumor activity by inducing mitochondria-mediated apoptosis and S-phase arrest in HepG2. Sci Rep 7: 46056, 2017.

53. Zhao H, Hu X, Cao K, Zhang Y, Zhao K, Tang C and Feng B: Synthesis and SAR of 4,5-dihydro-1H-pyrazolo[4,3-h]quinazoline derivatives as potent and selective CDK4/6 inhibitors. Eur J Med Chem 157: 935-945, 2018

54. Goel S, DeCristo MJ, Watt AC, BrinJones H, Sceneay J, Li BB, Khan N, Ubellacker JM, Xie S, Metzger-Filho O, et al: CDK4/6 inhibition triggers anti-tumour immunity. Nature 548: 471-475, 2017.

55. Finn RS, Crown JP, Lang I, Boer K, Bondarenko IM, Kulyk SO, Ettl J, Patel R, Pinter T, Schmidt M, et al: The cyclin-dependent kinase 4/6 inhibitor palbociclib in combination with letrozole versus letrozole alone as first-line treatment of oestrogen receptor-positive, HER2-negative, advanced breast cancer (PALOMA-1/TRIO-18): A randomised phase 2 study. Lancet Oncol 16: 25-35, 2015 
56. Cristofanilli M, Turner NC, Bondarenko I, Ro J, Im SA, Masuda N, Colleoni M, DeMichele A, Loi S, Verma S, et al: Fulvestrant plus palbociclib versus fulvestrant plus placebo for treatment of hormone-receptor-positive, HER2-negative metastatic breast cancer that progressed on previous endocrine therapy (PALOMA-3): Final analysis of the multicentre, double-blind, phase 3 randomised controlled trial. Lancet Oncol 17: 425-439, 2016.

57. Krimpenfort P, Ijpenberg A, Song JY, van der Valk M, Nawijn M, Zevenhoven $\mathrm{J}$ and Berns A: p15Ink4b is a critical tumour suppressor in the absence of p16Ink4a. Nature 448: 943-946, 2007.

58. Nanda V, Downing KP, Ye J, Xiao S, Kojima Y, Spin JM, DiRenzo D, Nead KT, Connolly AJ, Dandona S, et al: CDKN2B regulates TGF $\beta$ signaling and smooth muscle cell investment of hypoxic neovessels. Circ Res 118: 230-240, 2016.
59. González-Sarrías A, Ma H, Edmonds ME and Seeram NP: Maple polyphenols, ginnalins A-C, induce S- and G2/M-cell cycle arrest in colon and breast cancer cells mediated by decreasing cyclins A and D1 levels. Food Chem 136: 636-642, 2013.

(i) (5) This work is licensed under a Creative Commons Attribution-NonCommercial-NoDerivatives 4.0 International (CC BY-NC-ND 4.0) License. 